\title{
Effect of Storage (in small Packages) on Volatile Oil and Piperine Content of Ground Black Pepper
}

\author{
E. V. PACKIYASOTHY, S. BALACHANDRAN AND E. R. JANSZ \\ Natural Products Section, Ceylon Institute of Scientific and Industrial Research, \\ P.O. Box 787, Colombo, Sri Lanka.
}

(Date of receipt: 24 November 1982)

(Date of acceptance : 05 July 1983)

\begin{abstract}
The composition of the essential oil of Sri Lanka black pepper and changes in composition on grinding and storage in various packaging materials are reported.
\end{abstract}

\section{Introduction}

Pepper (Piper nigrum L.) is one of the more important spices grown in Sri Lanka. Sri Lanka pepper is reported to have special characteristics ${ }^{6}$ (high volatile oil and piperine) which gives it a special position in world trade. Traditionally, pepper has been exported as whole black pepper, however with increasing competition in the world market the need for product diversification has arisen. Among the new forms of pepper for the export market are: ground pepper (black and white), canned and pickled green pepper, buff and white pepper (containing pericarp) and dried green pepper. ${ }^{8}$

The original systematic study of the volatile constituents of pepper by Jennings and co-workers ${ }^{8,9,11,12,13,15}$ was carried out using Sri Lanka pepper. However, these studies were directed mainly towards the confirmation of the presence and identification of the constituents of the volatile oil. Although one study ${ }^{16}$ gave a quantitative picture of the oil of Sri Lanka pepper, the report is nearly 20 years old. Indian varieties, on the other hand, have been extensively studied and the subject has been given much prominence in a recent review. 6

Thus there is a case for investigating the composition of volatile constituents of Sri Lanka pepper based on gas-liquid chromatography notwithstanding the fact that the subject was considered in part in a paper on quality control.15

'Past studies $1,2,3,4$ on the packaging of ground black pepper have revealed that polyethylene alone does not fully meet the requirements of a ground pepper and in order to retain volatiles, select laminates must be used. Chinenova et al ${ }^{4}$ reported reduced losses in lacquered cellophane, while Balsubrahmanyam et al ${ }^{3}$ found that low density polyethylene (LDPE) and high density polyethylene (HDPE) were poor barriers for volatile oil while ground pepper in a polyester/polyethylene lined carton 
lost the least oil. Balsubrahmanyam and $\mathrm{Kumar}^{2}$ reported a 5 month-shelf life using a paper / aluminium foil/ polyethylene laminate as well as a cellophane / LDPE double pouch. Balsubrahmanyamet al 'also reported that high temperature storage in LDPE and HDPE resulted in 'sticky' packages and oil deposition on the surface of the packaging material.

Despite this knowledge, ground pepper continues to be marketed in Sri Lanka in single pouch LDPE.

Our study on packaging of this material appeared important for two reasons:-

(i) To our knowledge the effect of storage in various packaging material on essential oil composition has thus far not been reported.

(ii) It was of interest to determine in more detail the shelf-life of ground pepper in LDPE as this was the packaging material currently in use in this country.

In this paper we report the following:

(i) A glc analysis of Sri Lanka pepper vil,

(ii) The effect of commercial grinding on volatile oil content and composition,

(iii) An analysis of volatile oil of selected ground pepper samples found in the local market.

(iv) The effect of storage of ground pepper in different gauges of single pouch LDPE packs, an Al foil laminate and tinned cans on the composition of pepper oil.

(v) The effect of storage (in these packages) on piperine (the pungent principle of pepper).

\section{Experimental}

\subsection{Raw material}

Graded black pepper (FAQ) meant for the export market was purchased from G. S. Chatoor and Co.,Ltd. Other samples were collected from Wariyapola Group Estate, Matale (a plantation of genuine and unmixed Sri Lanka pepper). The latter was dried at $50-60^{\circ} \mathrm{C}$ in a forced draft oven for $48 \mathrm{~h}$. Ground pepper samples from different sources were purchased from the open market. 


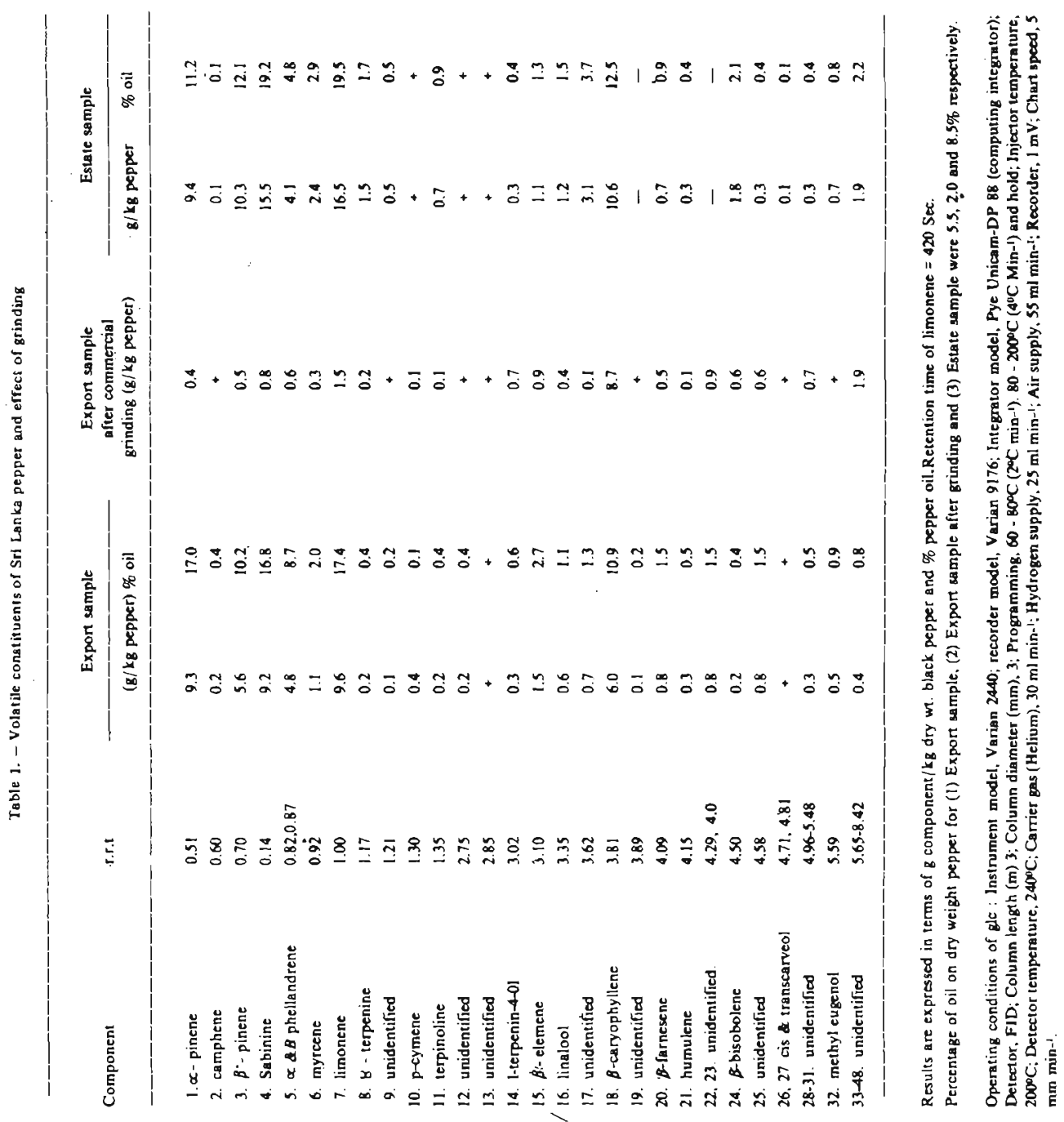




\subsection{Grinding and packing}

Black pepper was ground in a commercial hammer mill and sieved ( $150 \mu \mathrm{m}$ sieve). The ground pepper $(250 \mathrm{~g})$ was immediately packed in the following packages:

(i) $\mathrm{LDPE}-25,50,75,100,125$ and $175 \mu \mathrm{m}$ (ii) HDPE - $15 \mu \mathrm{m}$ (iii) Al foil $(0.1$ $\mathrm{mm}$ ) / LDPE $75 \mu \mathrm{m}$ laminate (iv) lacquered tinned cans. These packages were stored in a wooden cupboard at ambient temperature $\left(27-31^{\circ} \mathrm{C}\right)$.

\subsection{Moisture content}

Moisture content was determined by the Dean and Stark (toluene) method. 5

\subsection{Oil content}

Oil content was determined using Clavenger light oil arm after hydro-distillation for $4 \mathrm{~h}$. For the determination of oil content grinding was preceded by freezing. This procedure prevented oil loss.

\subsection{Oil composition}

Oil composition was determined using a Varian 2440 gas chromatograph. Operating and other conditions are given in a footnote of Table 1. Identifications were made using retention data and peak enrichment techniques only. This has been considered adequate as all the components tentatively identified have been previously reported in pepper oil.

\subsection{Piperine content}

Pepper was extracted with $\mathrm{CH}_{2} \mathrm{Cl}_{2}$ and pepper oleoresin produced as described previously? ' Piperine was estimated by the two methods detailed previously: (i) tlc-uv densitometric method ${ }^{7}$ and (ii) the tlc-uv spectrophotometric method!"

\section{Results}

\subsection{Oil composition of Sri Lanka pepper oil}

Oil composition of an export sample' and a sample collected from an estate is shown in Table 1 . As reported previously ${ }^{6.16^{\circ}}$ monoterpene hydrocarbons were present in relatively large proportions. A significant peak appeared immediately prior to $\beta_{-}$ 
caryophyllene (r.r.t = 3.62) conspicuous in Sri Lanka pepper and sometimes occurring in very large proportions. The peak, not reported previously, was unidentified. Beyond r.r.t. $=5.6$ were $15-20$ minor components whose total contribution was $<.8 \%$. No effort was made to identify these components.

\subsection{Effect of Grinding}

Table 1 also shows the effect of grinding where the levels of monoterpene hydrocarbons declined to the greatest extent. It appears that some caryophyllene or a chromatographically similar sesquiterpene was formed during grinding.

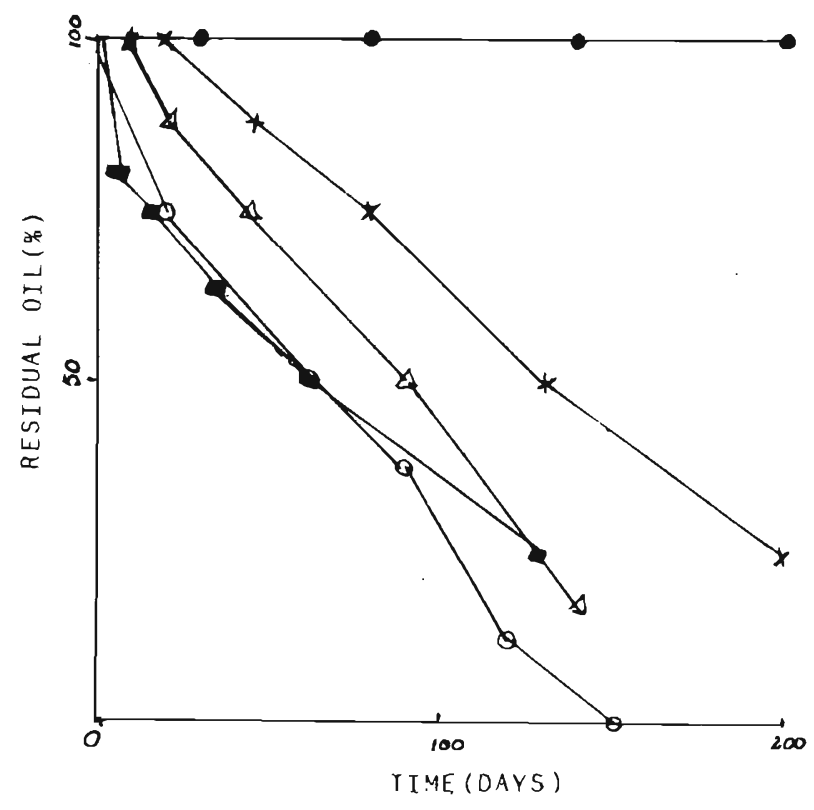

Figure 1 - Effect of storage in polythene on oil content of ground pepper

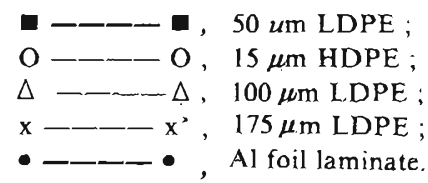




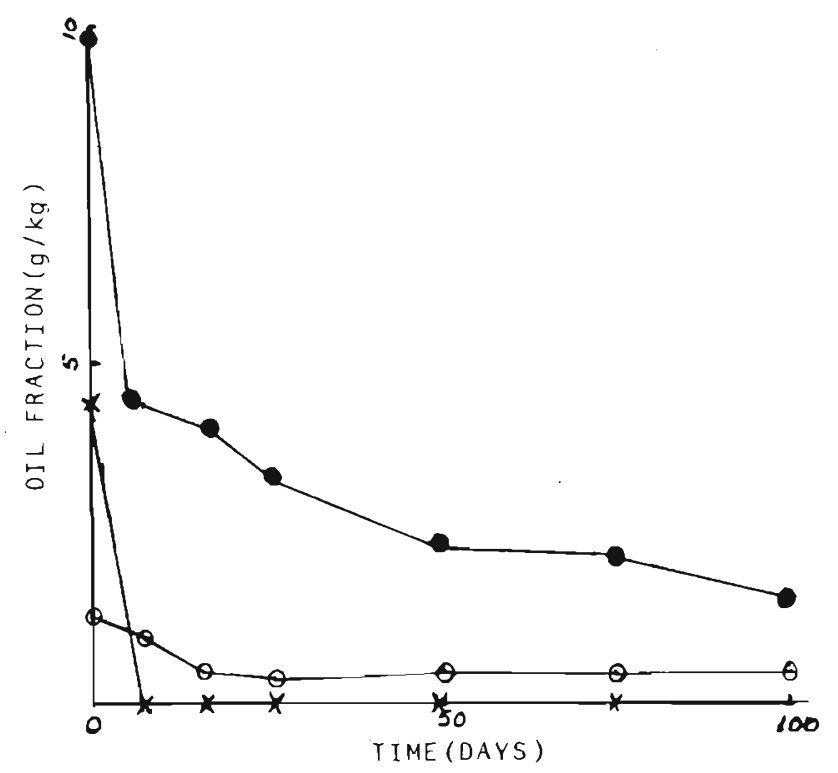

Figure 2 - Loss of oil fractions of ground pepper from 25 um L.DPE

$\mathrm{x}-\cdots-\mathrm{x}$, Monoterpene hydrocarbons ;

- - - • , Sequiterpene hydrocarbons ;

$\mathrm{O}-\mathrm{C}-\mathrm{O}$, Oxygenates.

Only known components are categorised

Monoterpene hydrocarbons:

$\propto$-pinene, $\boldsymbol{\beta}$-pinene, camphene, sabinene, $\propto$-phellandrene, $\beta$-phellandrene, myracene, limonene, $\gamma$-terpenene, p-cymene, terpinolene

Sesquiterpene hydrocarbons:

$\beta$-caryophyllene, $\beta$-farnesene, humulene, $\beta$-bisobolene, $\beta$-elemene

Oxygenates:

1-terpenin-4-ol, linalool, cis and trans carveol, methyl eugenol

\subsection{Analysis of samples of ground pepper from the market}

Four samples were analysed. Samples 1-3 were ground black pepper contained in 50 micron LDPE while sample 4 was contained in a bottle fitted with a crown cork. The latter sample contained $0.6 \%$ oil while the other samples contained $0.1 \%$ oil or less. On glc analysis it was found that monoterpene hydrocarbons were absent in all cases. 


\subsection{Storage experiments using ground pepper}

\subsubsection{Preliminary observations}

Moisture content was initially $8 \%$. After the various stages of storage, moisture content rose to $9-14 \%$. Mouldiness was not visually observed.

\subsubsection{Effect on oil content}

Oil content declined markedly under all LDPE and the HDPE storage conditions but remained constant in the aluminium foil laminate and in the tinned can. Some of the results are expressed in Figure $1 .(50 \mu \mathrm{m}, 100 \mu \mathrm{m}$ and $175 \mu \mathrm{m} \mathrm{LDPE}, 15 \mu \mathrm{m}$ HDPE and Al foil laminate).

\subsubsection{Effect on oil composition}

Here selected known components were combined under the following categories: (1) monoterpene hydrocarbons, (ii) sesquiterpene hydrocarbons and (iii) oxygenates.

In all cases a greater loss of monoterpene hydrocarbons was observed. Sesquiterpene hydrocarbons were also lost, but at a less rapid rate. On a percentage basis the smallest losses appeared to be exhibited by the oxygenates. Figures 2, 3 and 4 describe the rate of loss of volatile oil fractions from $\operatorname{LDPE}(25 \mu \mathrm{m}) \operatorname{LDPE}(175 . \mu \mathrm{m})$ and HDPE $(15 \mu \mathrm{m})$. Losses of monoterpene hydrocarbons were also shown in the $\mathrm{Al}$ foil laminate and tinned cans after six months of storage; as total oil content did not decline in these cases, the loss of this fraction is probably due to its conversion into other volatiles.

Table 2 describes the changes in composition of oil after different treatments and illustrates that the degree of loss of constituents is preferential.

\subsubsection{Effect on piperive content}

Both methods of assay of piperine used in this study gave very closely concordant results.

The only significant decline in piperine content was in the $25 \mu \mathrm{m}$ LDPE (Figure 5). The figure also shows the loss of volatile oils from the same package. Volatile oil and piperine losses closely parallel one another. 


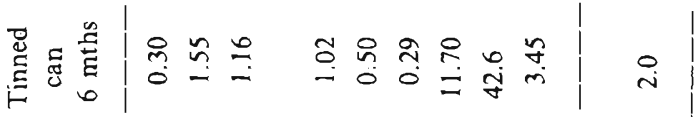

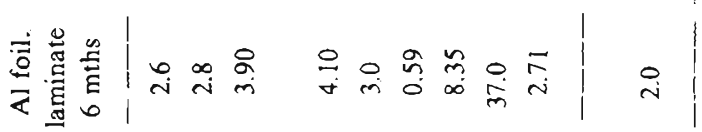

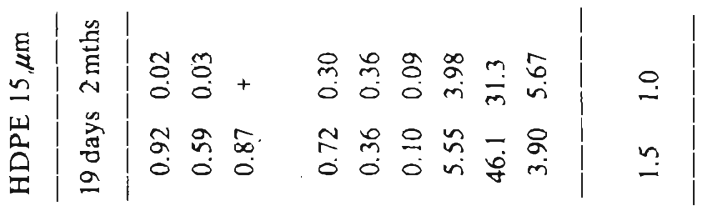

E|

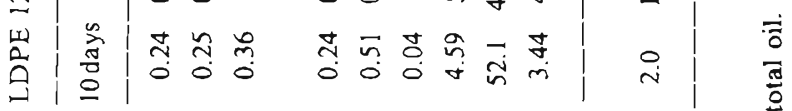

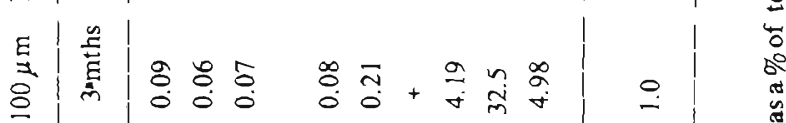

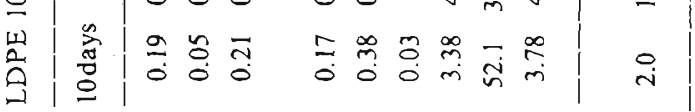

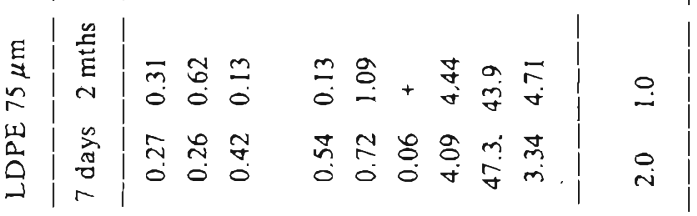

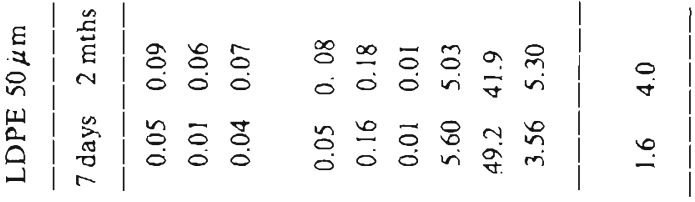

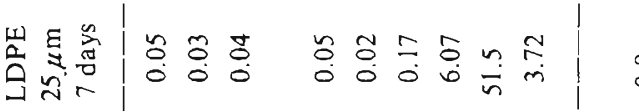

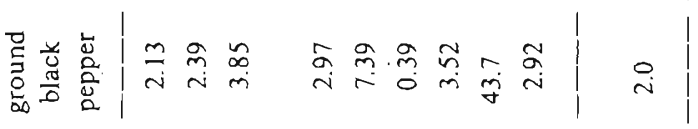

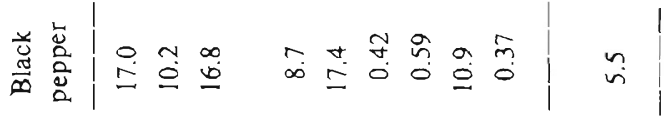

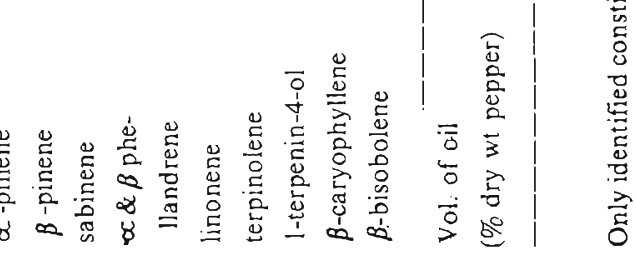




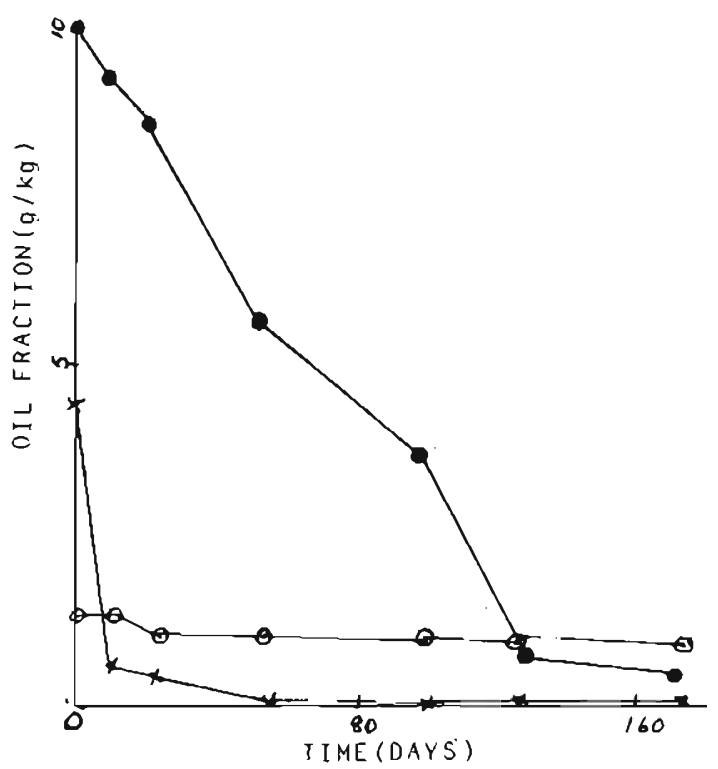

Figure 3 - Loss of oil fractions of ground pepper from $175 \mu \mathrm{m}$ LDPI For details see Figure 2.

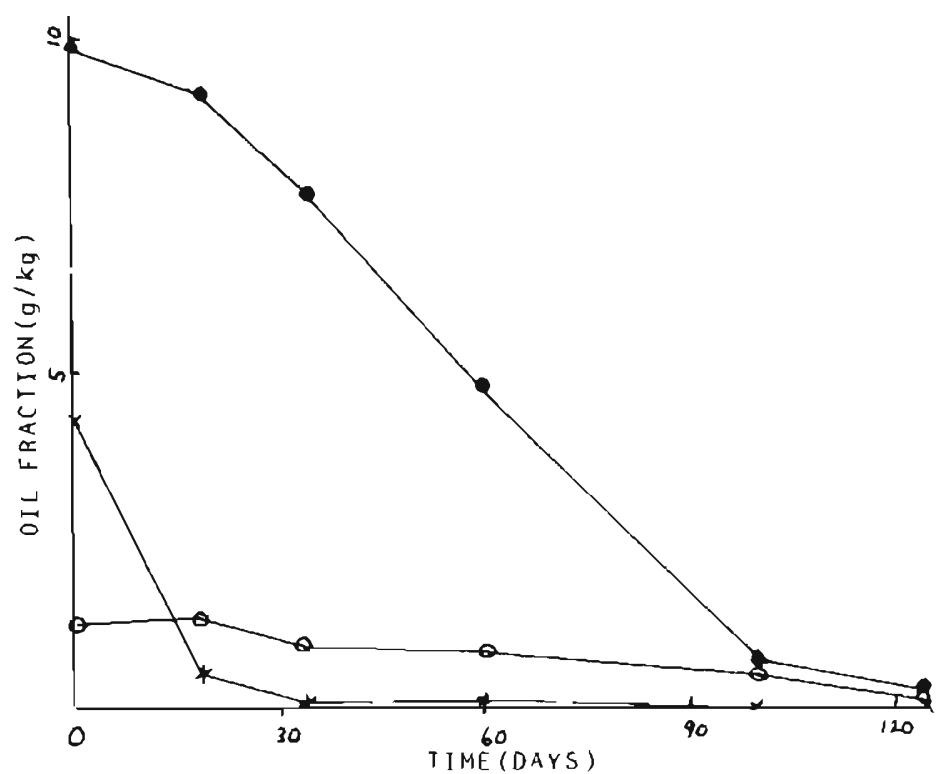

Figure $4-$ Loss of oil fraction of ground pepper from $15 \mu \mathrm{m} \mathrm{HDPE}$ For detaits see Figure 2. 


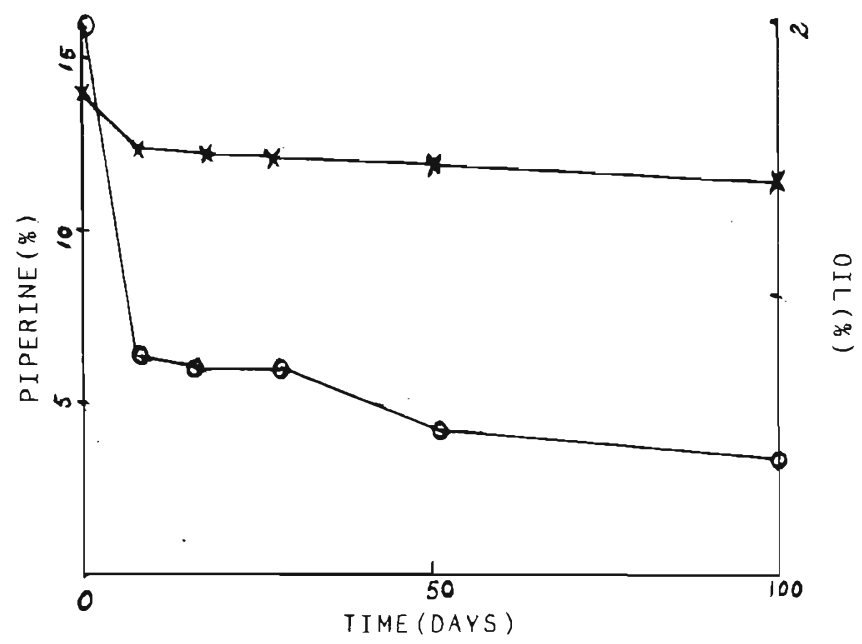

Figure 5 - Loss of oil and piperine from ground pepior on storage in $25 \mu \mathrm{m}$ LDPl:

$\mathrm{x}-\cdots-\mathrm{x}, \%$ piperine

$\mathrm{O}-\ldots-\mathrm{O}, \%$ volatile oil

The piperine levels of the $50 \mu \mathrm{m}$ LDPE packaged pepper showed a small decline $(5 \%)$, while no significant decline in piperine content was shown in the case of the other packaging materials.

On washing the outer surface of $25 \mu \mathrm{m}$ LDPE with ether, two major components were isolated: (i) piperine-separated by tlc and its identity verified by its uv spectrum and (ii) caryophyllene oxide (tentatively identified by glc and tlc techniques).

\section{Discussion}

The composition of Sri Lanka pepper oil does not differ significantly from that reported by the original study of Jennings and Wrolstad. ${ }^{16}$ However special attention must be drawn to the additional peak at r.r.t $=3.62$ which appears to be characteristic of and unique to Sri Lanka pepper oils. This peak has not been identified.

Results show that milling and packaging conditions markedly affect oil content as well as composition. The absence of volatile constituents in the samples from the open market illustrates two facts viz.: (i) little attention is being paid to the method of packaging of ground pepper and (ii) the absence of volatiles does not appear to be an important consideration in local consumer tastes. 
However, this will not be true for products destined for the export market. Here, cold or otherwise controlled milling will be required to minimize heat generation and packaging materials will need to be chosen according to the requirements of shelflife. This does not necessarily rule out the use of LDPE as preferential loss of monoterpene hydrocarbons and thereby an increase in concentration of oxygenates among the volatiles could result in a product more preferred organoleptically.

The study, confirms that both LDPE and HDPE are poor barriers for essential oils and that the thickness of LDPE has a significant effect on not only the rate of loss of oil but also the composition of the residual volatiles.

The loss of piperine from the 25 micron LDPE is interesting and it is theorised that this compound migrates through the polyethylene facilitated by the movement of oil through the barrier. The detection of caryophyllene oxide on the outer surface of the pouch is not surprising and probably arises by the oxidation of $1 \beta$-caryophyllene; while the less volatile caryophyllene oxide is retained on the outer surface of the pouch to some extent, the other hydrocarbons are volatalised.

\section{Acknowledgements}

The authors thank the Dircctor. C.cylon Institute of Scientific and Industrial Rescalch (CISIR) for facilities provided, and the Natural Resources, Energy and Science Authority for a stipend for a Rescarch Assistant (RG 82/17). Also acknowledged are Misscs Dinapali de Zoysa and Ramani Perera for secretarial assistance. Mrs. Dilmani Warnasuriya for library services and the Publications Committec, CISIR for valuable comments.

\section{References}

1. BAL.SUBRAHMANYAM, N. \& KUMAR K. R. (1970). In "Pepper and Pepper products - an annotated bibliography 1970 - 80". CFTRI, Mysore, India p 9.

2. Balsubrahmanyam, N.. MAHADEVIALI, B. \& ANANDASWAMY, B. (1978). Indian Spices, $15: 6$.

3. BALSUBRAHMANYAM, N., BALDEV, R., INDIRAMMA, A. R. \& ANANDASWAMY, B. (1980). Indian Spices 18: 15 .

4. Chinenova, E. G., ZOlOedova.S. F., REINGACH, B. Y. \& TITOVA, V. I. (1970). Fd. Sci. Technol, Abser. 2: 245 .

5. DEAN, E. W. \& STARK, D. D. (1970). Ind. Eng. Chem. 12: 486.

6. GOVINDARAJAN, V. S. (1977). CRC critical reviews in Fd. and Nutr., 9: 115.

7. JANSZ, E. R., PATHIRANA. I. C., \& PACKIYASOTHY E. V. (1982). III press: 
8. LEWIS, Y. S., KRISHNAMURTHY, N., NAMBUDIRI, E. S., SANKARI KULtiamMA, B., SHIVASHANKER, S. \& MATHEW, A. G. (1976). In, "Report on Int. Seminar on Pepper" Cochin, India. Spice Export Promotion Council pp 49-54.

9. Muller, C. J., CREveling, C. K. \& JenNings, W. S. (1968). J. Agric. Fd. Chem. 16:113

10. MUller, C. J. \& JenNings, W. G. (1967). J. Agric. Fd. Chem. 15:762

11. PATHIRANA, I. C. \& JANSZ, E. R. (1981). Proceedings, 10th Annual Session, Institute of Chemistry, Sri Lanka 11.

12. RICHARD, H. M. \& JENNINGS, W. G. (1971) J. Fd. Sci. $36: 584$

13. Russel, G. F., MURRAY, W. J., MUller, C. J. \& JenNingS, W. G. (1968). J. Agric. Fd. Chem. 16: 1049.

14. RUSSEL, G. E. \& JENNINGS, W. G. (1969). J. Agric. Fd. Chem. 17: 1107.

15. WIJESEKARA, R. O. B., SENANAYAKE, U. M. \& JAYEWARDENE, A. L. (1972). Flovour Ind., $3: 133$.

16. Wrolstad, R. E. \&.JENNINGS, W. G. (1965). J. Fd. Sci, 30: 274. 